\title{
Long non-coding RNA cartilage injury-related promotes malignancy in bladder cancer
}

\author{
XUEBAO XIANG ${ }^{1}$, JIEFU HUANG ${ }^{1}$, WENFA MO $^{2}$, LEIMING JIANG ${ }^{1}$, WENGUO SUN $^{1}$ and PENGCHENG LI ${ }^{3}$ \\ Departments of ${ }^{1}$ Urology and ${ }^{2}$ Pathology, Affiliated Hospital of Guilin Medical College, Guilin, Guangxi 541001; \\ ${ }^{3}$ Department of Urology, Henan Province People's Hospital, Zhengzhou, Henan 450000, P.R. China
}

Received June 30, 2017; Accepted November 21, 2017

DOI: $10.3892 / \mathrm{ol} .2017 .7678$

\begin{abstract}
Recent advances have highlighted the important roles of long non-coding RNAs (lncRNAs) in a number of biological processes, including oncogenesis. However, the function of lncRNA cartilage injury-related (lncRNA-CIR) in bladder cancer progression remains elusive. A novel function for lncRNA-CIR in bladder cancer was identified in the present study. Reverse transcription quantitative polymerase chain reaction, viability, invasion assay and in vivo implantation were used to evaluate the role of lncRNA-CIR. It was identified that the expression of IncRNA-CIR was frequently upregulated in 52 cancerous tissues and selected bladder cancer cell lines. Additionally, upregulating lncRNA-CIR was demonstrated to promote viability and invasion in T24 and SW780 cells, whereas siRNA-mediated lncRNA-CIR-knockdown consistently exhibited the opposite effects. High lncRNA-CIR levels also dictated poor overall survival among patients with bladder cancer. Furthermore, in vivo implantation experiments also supported a tumorigenic function for lncRNA-CIR, as decreasing lncRNA-CIR levels markedly attenuated Ki-67 staining and xenograft tumor growth. Overall, the present study identified a novel function of IncRNA-CIR and indicates that IncRNA-CIR may serve as a potential biomarker for bladder cancer treatment.
\end{abstract}

\section{Introduction}

Bladder cancer is among the most detrimental tumors of the urinary system, particularly in China (1). A total of $\sim 70 \%$ of patients belong to the non muscle-invasive bladder cancer group and $<50 \%$ of patients will suffer from recurrence; furthermore, $\sim 20 \%$ will progress to the muscle-invasive bladder cancer type (2). The incidence and mortality rates of patients with bladder cancer have markedly increased in recent

Correspondence to: Dr Jiefu Huang, Department of Urology, Affiliated Hospital of Guilin Medical College, 15 Lequn Road, Guilin, Guangxi 541001, P.R. China

E-mail: huangjf_gmc@163.com

Key words: long non-coding RNA cartilage injury-related, long non-coding RNA, bladder cancer, survival years (3). Numerous therapeutic methods for bladder cancer intervention have been investigated, including chemotherapy, radiotherapy and surgery; however, the overall survival (OS) rate remains poor (4). Therefore, identifying novel biomarkers for an early diagnosis and effective prognosis, as well as establishing the underlying mechanisms for bladder cancer progression, is critically important for increasing the survival rate among patients with bladder cancer.

The occurrence and development of bladder cancer has been ascribed to multiple mechanisms. For example, frequent inactivation of tumor suppressor pathways, including the p53 signaling pathway, contributes to bladder cancer progression (5). Similarly, aberrant activation of oncogenic pathways, including the Akt and mitogen-activated protein kinase pathways, has also been reported to increase motility and invasion in bladder cancer (6). Furthermore, epigenetic alterations, including loss of heterozygosity, hypermethylation and point mutations, have also been implicated in the development of multifocal bladder cancer $(7,8)$. Notably, factors involved in chromosome abnormalities such as C14orf166 also function as high-risk biomarkers for bladder cancer progression (9). However, the intrinsic cellular mechanisms remain largely elusive and further studies are required to elucidate the mechanisms of bladder cancer development.

Although research regarding small non-coding NRAs (e.g., microRNAs) has been the focus in the field of molecular biology, numerous studies have indicated that long non-coding RNAs (lncRNAs) also exhibit essential roles in biological processes including proliferation, senescence and apoptosis (10). LncRNAs belong to a class of RNAs that are $>200$ nucleotides in length with no protein coding activities (11). Despite their inability to encode proteins, lncRNAs can regulate various biological pathways and are characterized by their complex mechanisms of activity (12). The aberrant expression of lncRNAs is critically involved in a variety of diseases, particularly cancer. Previously, Liu et al (13) identified that lncRNA cartilage injury-related (lncRNA-CIR) may increase the degradation of chondrocyte extracellular matrix in osteoarthritis (OA). However, the precise function of lncRNA-CIR especially in bladder cancer progression remains unknown.

In the present study, the role of lncRNA-CIR in the pathogenesis of bladder cancer was examined. It was identified that IncRNA-CIR was frequently upregulated in bladder cancer. Higher lncRNA-CIR expression promotes the viability and 
invasion of bladder cancer cells. In addition, it was found that patients with higher lncRNA level were associated with poor overall survival. The lncRNA-CIR may consistently increase xenograft tumor growth in vivo. Overall, the results of the present study identified a novel and oncogenic role of IncRNA-CIR in bladder cancer and may provide important insights into potential therapeutic interventions targeting lncRNA-CIR.

\section{Materials and methods}

Cell culture and specimen collection. The present study used bladder cancer T24, SW780, UBC-40, 5637 and UM-UC-3 cells lines, in addition to the transformed cell line, SV-HUC-1. The cell lines were all purchased from the Shanghai Institute of Cell Biology (Shanghai, China) and were cultured in RPMI-1640 medium supplemented with 5\% fetal bovine serum (FBS), $200 \mathrm{U} / \mathrm{ml}$ penicillin and $50 \mathrm{mg} / \mathrm{ml}$ streptomycin (all Sigma-Aldrich; Merck KGaA, Darmstadt, Germany), and maintained in an incubator with $5 \% \mathrm{CO}_{2}$ at $37^{\circ} \mathrm{C}$. Matched fresh bladder cancer specimens and normal adjacent tissues were collected from 52 patients at The Affiliated Hospital of Guilin Medical College (Guilin, Guangxi, China) between February 2009 and March 2011. Following surgical resection, tissues were immediately stored at $-80^{\circ} \mathrm{C}$ until total RNA was extracted. None of the patients had received preoperative chemotherapy or radiotherapy prior to surgery. All patients provided written informed consent, and the research on human specimens was reviewed and formally approved by the Ethics Committee of the Affiliated Hospital of Guilin Medical College.

lncRNA-CIR-knockdown and-overexpression. The sequences of specific siRNAs targeting lncRNA-CIR were designed and synthesized by Sigma-Aldrich (Merck KGaA). The lncRNA-CIR fragment obtained by RNA extraction and $R T$ - $q P C R$ from bladder cancer cell lines, tissues and normal adjacent tissues was amplified by PCR as described in next section. The reaction conditions were: Initial denaturation at $95^{\circ} \mathrm{C}$ for $2 \mathrm{~min}$, followed by 35 cycles of denaturation at $95^{\circ} \mathrm{C}$ for $15 \mathrm{sec}$, annealing at $60^{\circ} \mathrm{C}$ for $30 \mathrm{sec}$ and extension at $72^{\circ} \mathrm{C}$ for $45 \mathrm{sec}$. The amplified products were extracted and purified using Qiaquick gel extraction kit (Qiagen, Valencia, CA, USA), and then digested with Hind III and Xho I. Following this, the products were cloned into the pcDNA3.1 vector. The correct constructs were verified by DNA sequencing and were used to transfect T24 and SW780 cells. The constructs were sequenced using standard procedures of dye terminator chemistry on a 3700 Sequencer (Applied Biosystems; Thermo Fisher Scientific, Inc., Waltham, MA, USA). Sequences were compared to sequences in Gene Bank using the Blast program (version 2.5.0; https://blast.ncbi.nlm.nih.gov/Blast.cgi). All siRNAs against lncRNA-CIR were designed and synthesized by Sigma-Aldrich; Merck KGaA. All transfections were performed using Lipofectamine ${ }^{\circledR} 2000$ (Invitrogen; Thermo Fisher Scientific, Inc., Waltham, MA, USA) according to the manufacturer's protocol. Briefly, cells were cultured with RPMI-1640 medium in a 24-well plate for $24 \mathrm{~h}$ at $37^{\circ} \mathrm{C}$. Prior to transfection, the medium was replaced with $200 \mu \mathrm{l} /$ well of medium without antibiotics and the cells were cultured for $24 \mathrm{~h}$ at $37^{\circ} \mathrm{C}$. The DNA or RNA interference Lipofectamine ${ }^{\circledR}$
2000 complex was prepared by mixing for $30 \mathrm{~min}$, and then $100 \mu \mathrm{l}$ of the complex was added to each well. The cells were cultured for $24 \mathrm{~h}$ at $37^{\circ} \mathrm{C}$ with normal RPMI-1640 medium and then subject to additional assays. The si-CIR sequences used were: si-CIR\#1, sense: 5'-GCGCUGAACGGACUGA-3', antisense: 5'-GACAGUCCGUUCAGC=3'; si-CIR\#2, sense: 5'-CGUCAACAAGGAGCA-3', anti-sense: 5'-AUGCUCCUU GUUG-3', si-CIR\#3: sense: 5'-CGAGAACUGCGUGGCA-3', anti-sense: 5'-AUGCCACGCAGUUCUC-3'.

RNA extraction and RT-qPCR. Total RNAs were isolated from T24 and SW780 cell lines and human specimens with TRIzol $^{\circledR}$ reagent (Thermo Fisher Scientific, Inc.) according to the manufacturer's protocol. Following cell lysis, $0.5 \mathrm{ml}$ chloroform (Sigma-Aldrich; Merck KGaA) was added and cells were maintained at $20^{\circ} \mathrm{C}$ for $5 \mathrm{~min}$. Centrifugation was performed at $15,000 \mathrm{x} \mathrm{g}$ at $4^{\circ} \mathrm{C}$ for $10 \mathrm{~min}$. The aqueous phase was transferred to another tube and $0.2 \mathrm{ml}$ isopropanol per $1 \mathrm{ml}$ TRIzol was added. Following incubation for $15 \mathrm{~min}$ at $20^{\circ} \mathrm{C}$, centrifugation was conducted at $10,000 \mathrm{x}$ g at $4^{\circ} \mathrm{C}$ for $10 \mathrm{~min}$. The RNA pellet was washed with $70 \%$ ethanol and the RNAs were dissolved using $0.05 \mathrm{ml}$ fresh water and incubated for 15 min. Isolated RNA was reverse-transcribed with Improm-II reverse transcription kit (Promega Corporation, Madison, WI, USA) according to the manufacturer's protocol. GAPDH was used as the control. Reactions were performed using the ABI PRISM ${ }^{\circledR} 7000$ Sequence Detection system (Applied Biosystems; Thermo Fisher Scientific, Inc.) according to the manufacturer's protocol. The expression of IncRNA-CIR was calculated by the $2^{-\Delta \Delta \mathrm{Cq}}$ method (14). The quantitative real-time PCR was performed using TaqMan Non-coding RNA Assays (Applied Biosystems; Thermo Fisher Scientific, Inc.). The reactions were initially denatured at $95^{\circ} \mathrm{C}$ for $2 \mathrm{~min}$, followed by 35 cycles of denaturation at $95^{\circ} \mathrm{C}$ for $15 \mathrm{sec}$, annealing at $60^{\circ} \mathrm{C}$ for $30 \mathrm{sec}$, and $72^{\circ} \mathrm{C}$ for $45 \mathrm{sec}$. The experiments were performed a minimum of three times. The primer sequences were as follows: IncRNA-CIR sense, 5'-GCGAGATGTTTA CG-3' and anti-sense, 5'-CTGATGGAGAGAT-3'; and GAPDH sense, 5'-GGTAGTCTGTCGAGTT-3' and anti-sense, 5'-ATG GTCGCTGAATCGAT-3'.

Transwell invasion assay. The invasion assay was performed using Transwell plates (pore size, $8 \mu \mathrm{m}$ ) with a Boyden chamber (Sigma-Aldrich; Merck KGaA). Transfected cells were washed twice with serum-containing RPMI-1640 medium (Sigma-Aldrich; Merck KGaA). A total of $1 \times 10^{5}$ T24 and SW780 cells were seeded onto the Transwell apparatus. Each insert was preloaded with Matrigel (50 $\mu \mathrm{g}$; Sigma-Aldrich; Merck KGaA). Cells were suspended in $100 \mu \mathrm{l}$ RPMI-1640 serum-free medium (Sigma-Aldrich; Merck $\mathrm{KGaA}$ ) and placed in the top chambers. RPMI-1640 medium (100 $\mu \mathrm{l}$; Sigma-Aldrich; Merck KGaA) containing 10\% fetal calf serum (Sigma-Aldrich; Merck KGaA) was added to the bottom chambers. The chambers were incubated for $24 \mathrm{~h}$ at $37^{\circ} \mathrm{C}$ with $5 \% \mathrm{FBS}$ in the lower chamber. Cells on the upper layer were removed by cotton buds and then washed with PBS. The cells that had invaded into the lower chambers were fixed with methanol for $15 \mathrm{~min}$ (Sigma-Aldrich; Merck $\mathrm{KGaA}$ ) and stained with $5 \%$ crystal violet for $30 \mathrm{~min}$ at $20^{\circ} \mathrm{C}$ (Sigma-Aldrich; Merck KGaA). The results were visualized 
by light microscopy (DFC500; Leica Microsystems GmbH, Wetzlar, Germany) and the final values represent the mean from three fields on the membrane. The results were visualized at magnification, x100. Experiments were performed in triplicate.

Cell viability assay. Cell Counting Kit-8 (CCK-8; Dojindo Molecular Technologies, Inc., Kumamoto, Japan) was used to evaluate cell viability. Following transfection with pcDNA, si-NC, pcDNA-CIR or si-CIR for $36 \mathrm{~h}, \mathrm{~T} 24$ and SW780 cells were re-suspended and seeded into a 96 -well plate at a density of $\sim 1 \times 10^{4} \mathrm{cell} / \mathrm{ml}$. CCK- 8 solution $(25 \mathrm{ml} /$ well $)$ was then added and the plate was incubated for $3 \mathrm{~h}$ at $37^{\circ} \mathrm{C}$. The viability was monitored once a day for 5 days. The optical density at $490 \mathrm{~nm}$ was used to determine cell viability with the Spectramax M5 microplate monitor (Molecular Devices, LLC, Sunnyvale, CA, USA) according to the manufacturer's protocol.

In vivo implantation assay. T24 cells transfected with pcDNA, si-NC, pcDNA-CIR or si-CIR for $36 \mathrm{~h}$ were continuously cultured in RPMI 1640 medium (Invitrogen; Thermo Fisher Scientific, Inc.) for an additional $24 \mathrm{~h}$ at $20^{\circ} \mathrm{C}$. The cells were then resuspended and $\sim 1 \times 10^{6}$ cells were injected subcutaneously into nude mice. A total of 40 mice (BALB/C; female; age, 4-5 weeks; mean weight, $15.6 \mathrm{~g}$ ) were used. Mice were housed at $\sim 20^{\circ} \mathrm{C}, 55-60 \%$ humidity, with a light-dark cycle of $12 \mathrm{~h}$. Ad libitum access to food and water was provided. The nude mice were obtained from the Model Animal Research Center (Nanjing, China). The Ethics Committee of Affiliated Hospital of Guilin Medical College approved the animal experiments. The volumes (length $\mathrm{x}$ width $\mathrm{x}$ height) of the tumors in vivo were recorded by external caliper every 3 days for 30 days. Animals were sacrificed when tumor volumes reached 2,000 $\mathrm{mm}^{3}$, or when animals lost $>20 \%$ of initial body weight. After 30 days post-injection, all mice were sacrificed by an overdose of sodium pentobarbital $(4 \%, 300 \mathrm{mg} / \mathrm{kg}$ with intraperitoneal injection; catalog no. 1507002; Sigma-Aldrich; Merck $\mathrm{KGaA}$ ) and the implants were immunostained with Ki-67 (Sigma-Aldrich; Merck KGaA). Following antigen retrieval in the supplied solution, the primary antibody against Ki-67 (catalog no. P6834; dilution, 1:1,000; Sigma-Aldrich; Merck $\mathrm{KGaA}$ ) was added and incubated for $30 \mathrm{~min}$ at $20^{\circ} \mathrm{C}$. The image was visualized using a CX31-LV320 light microscope at magnification, x100 (Olympus Corporation, Tokyo, Japan).

Statistical analysis. All statistical results are shown as the mean \pm standard deviation. Statistical significance was determined by Mann-Whitney test using SPSS version 16.0 (SPSS, Inc., Chicago, IL, USA) and $\mathrm{P}<0.05$ was used to indicate a statistically significant difference. One-way ANOVA was used to determine the statistical significance across multiple groups followed by Least Significant Difference post hoc comparison. Kaplan-Meier curves were evaluated by log-rank test. The contingency table for clinicopathological features was determined by Fisher's exact test.

\section{Results}

IncRNA-CIR is upregulated in bladder cancer tissues and cells. RT-qPCR was used to evaluate the expression of IncRNA-CIR
Table I. Association between CIR and clinicopathological features.

\begin{tabular}{|c|c|c|c|c|}
\hline \multirow[b]{2}{*}{$\begin{array}{l}\text { Clinicopathological } \\
\text { factor }\end{array}$} & \multirow[b]{2}{*}{$\mathrm{n}$} & \multicolumn{2}{|c|}{ CIR expression } & \multirow[b]{2}{*}{ P-values } \\
\hline & & $\begin{array}{l}\text { Low, } \mathrm{n} \\
(\%)\end{array}$ & $\begin{array}{l}\text { High, } \mathrm{n} \\
(\%)\end{array}$ & \\
\hline \multicolumn{5}{|l|}{ Age, years } \\
\hline$<60$ & 30 & $14(46.7)$ & $16(53.3)$ & 0.779 \\
\hline$\geq 60$ & 22 & $12(54.5)$ & $10(45.5)$ & \\
\hline \multicolumn{5}{|l|}{ Sex } \\
\hline Male & 24 & $11(45.8)$ & $13(54.2)$ & 0.391 \\
\hline Female & 28 & $15(53.6)$ & $13(46.4)$ & \\
\hline \multicolumn{5}{|l|}{ Metastasis } \\
\hline Absent & 23 & 17 (73.9) & $6(26.1)$ & $0.005^{\mathrm{a}}$ \\
\hline Present & 29 & $9(31.0)$ & $20(69.0)$ & \\
\hline \multicolumn{5}{|l|}{ Tumor size, $\mathrm{cm}$} \\
\hline$<3$ & 21 & $16(76.2)$ & $5(23.8)$ & $0.004^{\mathrm{a}}$ \\
\hline$\geq 3$ & 31 & $10(32.3)$ & $21(67.7)$ & \\
\hline \multicolumn{5}{|l|}{ Pathological grade } \\
\hline Low & 27 & $11(40.7)$ & $16(59.3)$ & 0.267 \\
\hline High & 25 & $15(60.0)$ & $10(40.0)$ & \\
\hline
\end{tabular}

${ }^{\mathrm{a}} \mathrm{P}<0.05$. The median value (4.0489) was used as the cutoff. CIR, cartilage injury-related. Fisher exact test was used to determine significance.

in bladder cancer tissues and corresponding normal adjacent tissues. The relative expression of lncRNA-CIR was quantified by dividing the value in bladder cancer tissues by the associated value in normal adjacent tissues. The results demonstrated that lncRNA-CIR was significantly upregulated in bladder cancer tissues (Fig. 1A). Notably, $>80 \%$ of tissues were overexpressed in IncRNA-CIR by $>2$-fold increase (Fig. 1B). The lncRNA-CIR expression was markedly associated with metastasis and tumor size $(\mathrm{P}=0.005$ and $\mathrm{P}=0.004$ respectively; Table I). However, IncRNA-CIR expression was not significantly associated with age, sex or pathological grade (Table I). The samples were classified into two groups based on the median value of expression (4.0489; Fig. 1C). The expression of IncRNA-CIR was further examined in bladder cancer cell lines and the level of IncRNA-CIR was demonstrated to be consistently significantly increased in cancer cell lines compared with that in normal cells (Fig. 1D). These results suggested lncRNA-CIR was overexpressed in bladder cancer cells and specimens. The T24 and SW780 cell lines were selected for further analysis as they displayed the highest IncRNA-CIR expression among the bladder cancer cell lines examined.

IncRNA-CIR levels are associated with poor survival. Next, whether lncRNA-CIR may dictate survival of patients with bladder cancer was investigated. The samples were divided into low and high CIR expression using the median value of 4.0489 as the cutoff. The results demonstrated that lower 
A
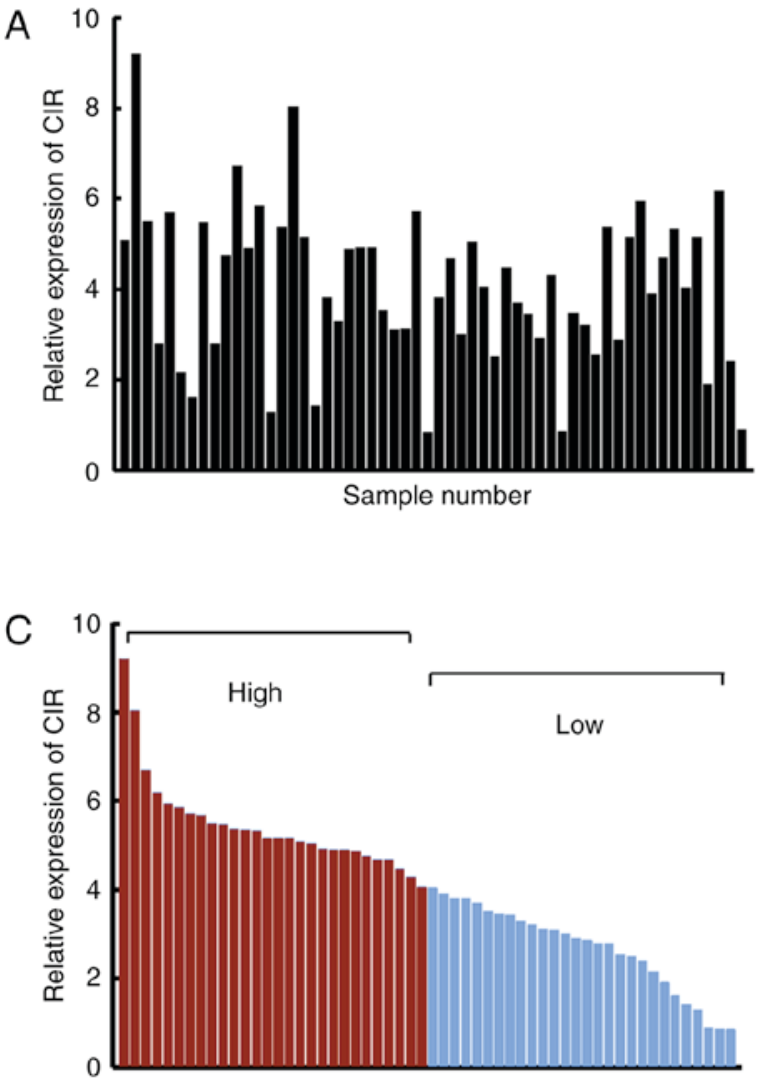

B

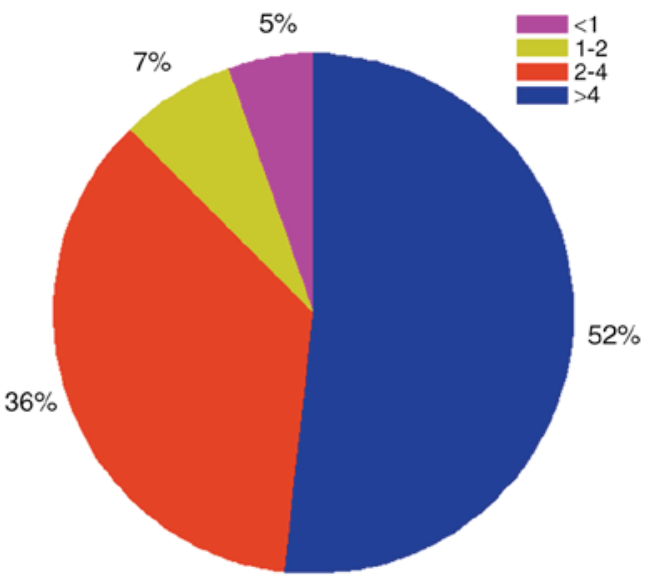

D

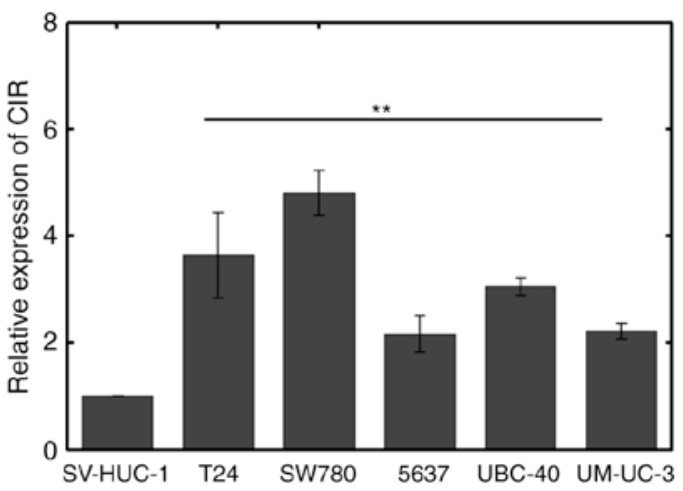

Figure 1. Expression of lncRNA-CIR in bladder cancer tissues and cell lines. (A) Relative expression of lncRNA-CIR in bladder cancer tissues normalized to corresponding normal adjacent tissues. (B) Percentage changes of relative expression of lncRNA-CIR in bladder cancer tissues normalized to corresponding normal adjacent tissues. (C) The samples were divided into two groups (i.e., high and low expression groups) by the median value 4.0489. (D) The expression of IncRNA-CIR in bladder cancer cell lines and the normal SV-HUC-1 cell line. One-way analysis of variance was used. ${ }^{* *} \mathrm{P}<0.01$ vs. SV-HUC-1. IncRNA-CIR, long non-coding RNA cartilage injury-related.

lncRNA-CIR expression was significantly associated with improved survival $(\mathrm{P}<0.01$; Fig. 2). Furthermore, the difference in OS rate between the two groups generally increased during the follow-up period (Fig. 2). These results suggested that higher lncRNA-CIR levels were associated with poor overall survival among patients with bladder cancer.

IncRNA-CIR promotes malignant phenotypes in bladder cancer cell lines. To further explore the potential oncogenic effect of lncRNA-CIR in vitro, a series of in vitro experiments were performed in the T24 and SW780 bladder cancer cell lines and lncRNA-CIR was demonstrated to be either knocked down or overexpressed in T24 and SW780 cells. The knockdown and overexpression efficiency were verified and the si-RNA-mediated knockdown and pcDNA-mediated transfection was demonstrated to significantly alter the expression of IncRNA-CIR compared with that in the corresponding control group (Fig. 3A). si-CIR\#1 displayed the most significant effect to knock down CIR expression in the two cells lines (Fig. 3A). Therefore, si-CIR\#1 was used for further analysis (abbreviated as si-CIR thereafter). CCK-8 assay was used to evaluate the viability of T24 and SW780 cells. Overexpressing lncRNA-CIR was demonstrated to significantly increase the viability of T24 cells (Fig. 3B). Decreasing lncRNA-CIR by si-RNA instead markedly inhibited the T24 cell viability compared with that in corresponding controls (Fig. 3B). Similar results were obtained in SW780 cells (Fig. 3C).

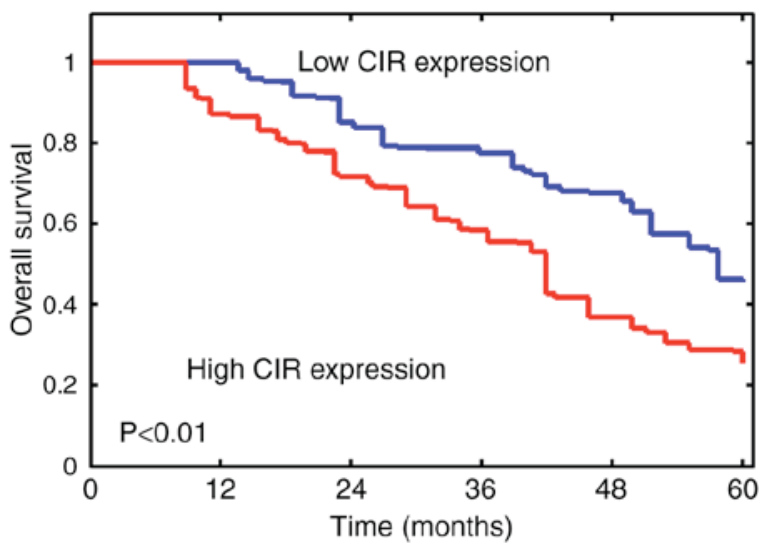

Figure 2. IncRNA-CIR promotes bladder cancer progression and dictates poor survival. The Kaplan-Meier survival curves for bladder cancer patients assessed by log-rank test. The patients with lower lncRNA-CIR expression displayed improved survival compared with the patients with high lncRNA-CIR expression $(\mathrm{P}<0.01)$. The median value (4.0489) was used as the cutoff. lncRNA-CIR, long non-coding RNA cartilage injury-related.

The invasion was further investigated and the present study identified that overexpression of IncRNA-CIR could significantly upregulate the invasive cell numbers of bladder cancer cells, while decreasing lncRNA-CIR expression displayed the opposite effect compared with that in the corresponding control group (Fig. 3D and E). These results indicated that 

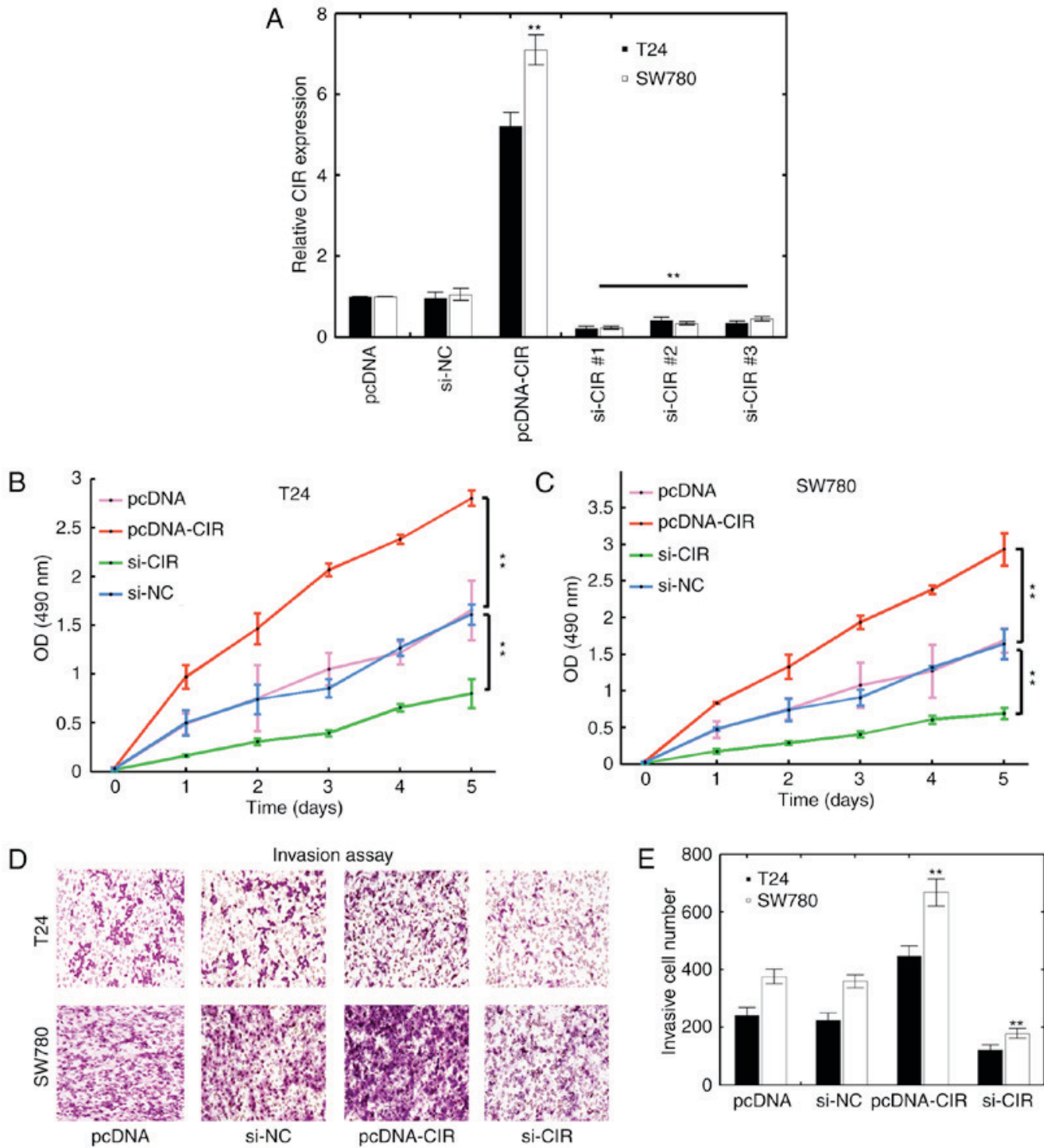

Figure 3. Inhibitory effect of lncRNA-CIR on bladder cancer cell lines. (A) The T24 and SW780 cells were transfected with pcDNA, pcDNA-CIR plasmid, si-NC or three si-CIR synthetics (si-CIR\#1, si-CIR\#2 and si-CIR\#3). IncRNA-CIR expression was then quantified using qPCR. One-way analysis of variance was used among si-NC group and the different si-CIR groups ( ${ }^{* *} \mathrm{P}<0.01$, the si-CIR groups covered by the black line vs the si-NC group). The Mann-Whitney test was used for comparison between the pcDNA and pcDNA-CIR groups. ${ }^{* *} \mathrm{P}<0.01$, pcRNA-CIR vs. pcDNA. The cell viability of (B) T24 and (C) SW780 cells was measured using Cell Counting Kit-8. The T24 and SW780 cells were transfected with pcDNA, si-NC, pcDNA-CIR or si-CIR. The Mann-Whitney test was used across the same time points. ${ }^{* * *} \mathrm{P}<0.01$. (D) Transwell invasion assay results for T24 and SW780 cells transfected with pcDNA, si-NC, pcDNA-CIR or si-CIR. (E) Quantification results for (D). ${ }^{* *} \mathrm{P}<0.01$, pcDNA-CIR vs. pcDNA group and si-CIR group vs. si-NC group. si, small interfering; NC, negative control; OD, optical density; CIR, cartilage injury-related.

IncRNA-CIR promotes the viability and invasion of bladder cancer cell lines in vitro.

LncRNA-CIR increases xenograft tumor proliferation and growth. To further ascertain whether lncRNA-CIR exhibited a tumorigenic effect in vivo, tumor implantation assays were performed. Approximately $1 \times 10^{6}$ T2 4 cells were subcutaneously injected into nude mice and the tumor volume was monitored every 3 days. It was observed that lncRNA-CIR overexpression substantially promoted tumor growth (Fig. 4A). However, reducing lncRNA-CIR expression markedly inhibited tumor growth compared with that in the control group (Fig. 4A). The solid tumors were resected and weighed at 30 days. The tumor weight in the lncRNA-CIR transfection group was significantly higher than that in the control group (Fig. 4B). Reduction in IncRNA-CIR expression by si-RNA-mediated knockdown was demonstrated to consistently decrease tumor weight (Fig. 4B). The Ki-67 staining indicative of cell proliferation also exhibited enhanced staining in the pcDNA-CIR transfection group, while the proliferation was significantly weakened with si-CIR-mediated knockdown compared with that in the control group (Fig. 4C). These results demonstrated that lncRNA-CIR can support tumor growth and further implied an oncogenic role of IncRNA-CIR in vivo.

\section{Discussion}

Due to the increasing progress in sequencing technology, lncRNAs have been demonstrated to be associated with 


\section{A}

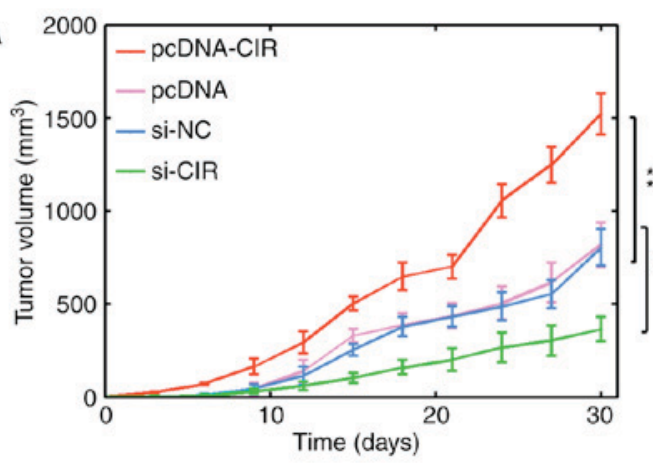

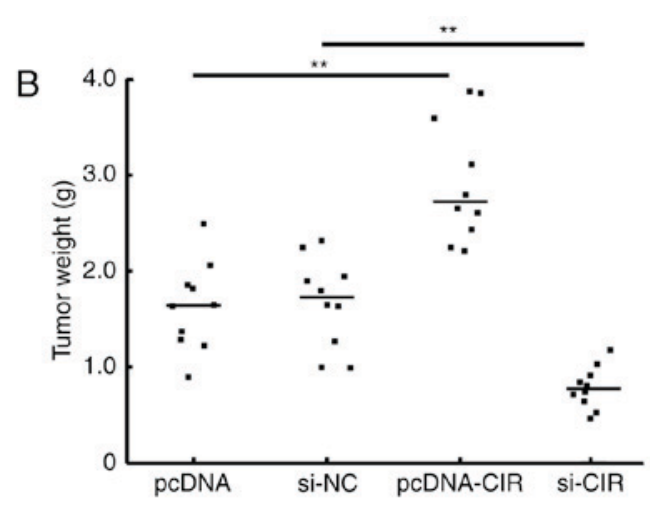

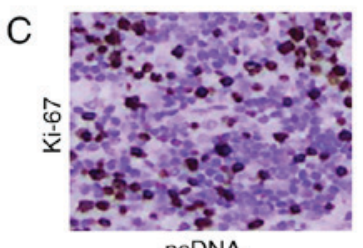

pcDNA

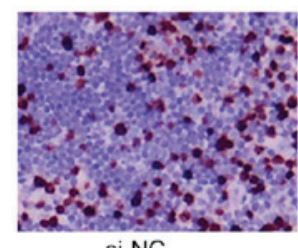

si-NC

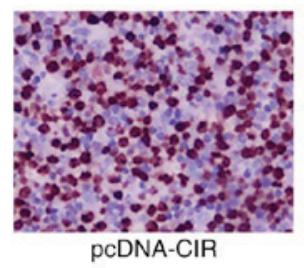

pcDNA-CIR

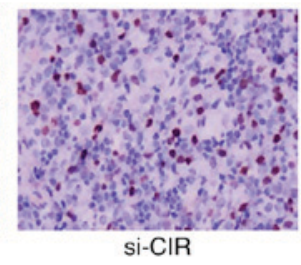

Figure 4. In vivo effect of 1 ncRNA-CIR. A total of $\sim 1 \times 10^{6} \mathrm{~T} 24$ cells transfected with pcDNA, si-NC, pcDNA-CIR or si-CIR were subcutaneously implanted into nude mice. (A) The in vivo tumor volume was measured every third day for 30 days. The Mann-Whitney test was conducted between si-NC and si-CIR groups or between pcDNA and pcDNA-CIR groups across the same time points. (B) Solid tumors were resected and weighed at the end of the implantation. ${ }^{* *} \mathrm{P}<0.01$. The Mann-Whitney test was used between si-NC and si-CIR groups or between pcDNA and pcDNA-CIR groups. (C) Tumors were retrieved and Ki-67 staining was performed (magnification, x200). The dark staining indicates enhanced proliferation. CIR, cartilage injury-related; si, small interfering; NC, negative control.

the pathology of various diseases, including cancer (15). Significant advances in lncRNA research have greatly enriched the level of understanding regarding lncRNA profiles. An increasing number of studies have implied that lncRNAs can exert a diverse range of functions in various types of tumors $(16,17)$. For example, lncRNAs may assist in classifying subtypes in glioma, colon and breast cancer (17). BRAF-activated LncRNA may suppress tumor development in papillary thyroid cancer (18). The lncRNA Gm15290 may instead promote invasion and proliferation of lung cancer via interactions with miR-615-5p (19). However, the mechanisms by which lncRNAs are involved in bladder cancer progression have not been fully identified. In the present study, an unexpected function of IncRNA-CIR in the development of bladder cancer was identified. IncRNA-CIR expression was demonstrated to be frequently upregulated in bladder cancer tissues and cell lines when compared with that in normal tissues and cell lines. Meanwhile, increasing lncRNA-CIR expression was also associated with poor survival and the malignant phenotypes of bladder cancer cells, including advanced proliferation, migration and invasion. The in vivo oncogenic effect for lncRNA-CIR was also confirmed, suggesting that lncRNA-CIR may exhibit a tumorigenic role in the present study.

A number of lncRNAs have been demonstrated to actively participate in bladder cancer development. For example, the lncRNA H19 is an imprinted gene and is highly associated with the risk of bladder cancer progression (20). Furthermore, lncRNA-UCA1 promotes bladder cancer cell invasion and migration by mediating the miR-145 pathway (21). The lncRNA-ABHD11-AS1 instead functions as a tumor suppressor IncRNA and can suppress malignant characteristics in bladder cancer (22). A well-known lncRNA, cancer susceptibility 2 (non-protein coding), was also shown to inhibit the migration and proliferation of bladder cancer cells in an in vitro study (23). The role of lncRNA-CIR, however, has never previously been investigated in bladder cancer, and therefore, to the best of our knowledge, the present study has presented for the first time the tumorigenic function of IncRNA-CIR in bladder cancer.

A limited number of studies have focused on lncRNA-CIR, particularly in cancer-associated research. A study by Liu et al (13) previously identified that IncRNA-CIR can specifically promote the degradation of chondrocyte extracellular matrix in osteoarthritis (OA). In OA cartilage, the expression of IncRNA-CIR is highly expressed among the 152 differentially expressed lncRNAs and regulates the expression of matrix metalloproteinase 13 and a disintegrin and metalloproteinase with thrombospondin motifs 5 (13). Silencing lncRNA-CIR may elevate the induction of collagen and aggrecan, while overexpressing lncRNA-CIR consistently raises the level of matrix-degrading enzymes (13). However, in the field of tumor biology, the implications of lncRNA-CIR have never been revealed. Hence, the results of the present study may broaden the understanding of lncRNAs in cancer research.

A number of the functions of lncRNAs have not yet been comprehensively identified. It has been argued that the RNA products from pseudogenes can induce mRNA degradation via the coding copies, which leads to the production of small RNAs (24). The long antisense transcripts generated from the pseudogenes can interact with the spliced counterparts and form double-stranded RNAs, which will be cleaved by Dicer (24). Therefore, the mRNAs that can encode proteins may instead promote the formation of RNA-induced silencing complex to consume additional copies of mRNAs and decrease the expression of protein-coding genes (25). 
The lncRNA-CIR is, however, a pseudogene product of vimentin (13) and may possibly serve as an siRNA to downregulate vimentin expression. Vimentin is known as an important factor in cell stiffness, the disruption of which may induce weakened cellular integrity and promote cell migration or invasion (26). Hence, we hypothesize that lncRNA-CIR may inhibit the expression of vimentin through the aforementioned mechanism and extracellular matrix degradation to promote the invasion of bladder cancer cells. Whether lncRNA-CIR also presents oncogenic roles in other types of tumor requires an in-depth investigation in the future.

There are also certain limitations in the present study. The clinical materials assessed were from Chinese patients only; lncRNA-CIR must be verified as a diagnostic and prognostic biomarker in different populations prior clinical usage. Additional multicenter studies that include diverse ethnic populations are required. In addition, the detailed molecular mechanism of lncRNA-CIR in bladder cancer was not identified. Additional studies are required to unravel the underlying mechanisms of lncRNA-CIR-mediated bladder cancer progression. Whether IncRNA-CIR serves a role in other types of cancer remains a focus for future studies.

In summary, the results of the present study suggest a tumorigenic role for IncRNA-CIR in bladder cancer. The involvement of lncRNA-CIR in bladder cancer progression may further extend the notion that many ncRNAs are critical modulators in diverse biological processes. Deciphering the complex codes in lncRNA fields may assist in unraveling the intrinsic complexity in tumor development and identifying effective therapeutics targeting important nodes in cancer intervention.

\section{References}

1. Kolodziej A, Krajewski W, Matuszewski M and Tupikowski K: Review of current optical diagnostic techniques for non-muscle-invasive bladder cancer. Cent European J Urol 69: $150-156,2016$.

2. D'Costa JJ, Goldsmith JC, Wilson JS, Bryan RT and Ward DG: A systematic review of the diagnostic and prognostic value of urinary protein biomarkers in urothelial bladder cancer. Bladder Cancer 2: 301-317, 2016.

3. Siegel RL, Miller KD and Jemal A: Cancer statistic, 2016. CA Cancer J Clin 66: 7-30, 2016.

4. Miller KD, Siegel RL, Lin CC, Mariotto AB, Kramer JL, Rowland JH, Stein KD, Alteri R and Jemal A: Cancer treatment and survivorship statistics, 2016. CA Cancer J Clin 66: 271-289, 2016.

5. Madka V, Mohammed A, Li Q, Zhang Y, Biddick L, Patlolla JM, Lightfoot S, Towner RA, Wu XR, Steele VE, et al: Targeting mTOR and p53 signaling inhibits muscle invasive bladder cancer in vivo. Cancer Prev Res (Phila) 9: 53-62, 2016.

6. Metalli D, Lovat F, Tripodi F, Genua M, Xu SQ, Spinelli M, Alberghina L, Vanoni M, Baffa R, Gomella LG, et al: The insulin-like growth factor receptor I promotes motility and invasion of bladder cancer cells through Akt- and mitogen-activated protein kinase-dependent activation of paxillin. Am J Pathol 176: 2997-3006, 2010.

7. Muto S, Horie S, Takahashi S, Tomita K and Kitamura T: Genetic and epigenetic alterations in normal bladder epithelium in patients with metachronous bladder cancer. Cancer Res 60: 4021-4025, 2000.

8. van Kessel KE, Van Neste L, Lurkin I, Zwarthoff EC and Van Criekinge W: Evaluation of an epigenetic profile for the detection of bladder cancer in patients with hematuria. J Urol 195: 601-607, 2016.
9. Chen M, Ye Y, Zou B, Guo S, Zhou F, Lu K, Liu J, Xu Z, Han H, Liu Z, et al: C14orf166 is a high-risk biomarker for bladder cancer and promotes bladder cancer cell proliferation. J Transl Med 14: 55, 2016.

10. Hata A and Kashima R: Dysregulation of microRNA biogenesis machinery in cancer. Crit Rev Biochem Mol Biol 51: 121-134, 2016.

11. Tani H, Imamachi N, Mizutani R, Imamura K, Kwon $\mathrm{Y}$, Miyazaki S, Maekawa S, Suzuki Y and Akimitsu N: Genome-wide analysis of long noncoding RNA turnover. Methods Mol Biol 1262: 305-320, 2015.

12. Kit OI, Kirichenko EY, Kirichenko YG, Novikova IA, Selyutina ON and Filippova SY: The long non-coding RNA associated with cancerogenesis: biological significance and perspectives of application in diagnostic. Klin Lab Diagn 61: 13-16, 2016.

13. Liu Q, Zhang X, Dai L, Hu X, Zhu J, Li L, Zhou C and Ao Y: Long noncoding RNA related to cartilage injury promotes chondrocyte extracellular matrix degradation in osteoarthritis. Arthritis Rheumatol 66: 969-978, 2014.

14. Livak KJ and Schmittgen TD: Analysis of relative gene expression data using real-time quantitative PCR and the 2(-Delta Delta C(T)) method. Methods 25: 402-408, 2001.

15. Feng N, Wang Y, Zheng M, Yu X, Lin H, Ma RN, Shi O, Zheng X, Gao M, Yu H, et al: Genome-wide analysis of DNA methylation and their associations with long noncoding RNA/mRNA expression in non-small-cell lung cancer. Epigenomics, 2017 (Epub ahead of print).

16. Deng H, Zhang J, Shi J, Guo Z, He C, Ding L, Tang JH and Hou Y: Role of long non-coding RNA in tumor drug resistance. Tumour Biol 37: 11623-11631, 2016.

17. Flippot R, Malouf GG, Su X, Mouawad R, Spano JP and Khayat D: Cancer subtypes classification using long non-coding RNA. Oncotarget 7: 54082-54093, 2016.

18. Liao T, Qu N, Shi RL, Guo K, Ma B, Cao YM, Xiang J, Lu ZW, Zhu YX, Li DS and Ji QH: BRAF-activated LncRNA functions as a tumor suppressor in papillary thyroid cancer. Oncotarget 8: 238-247, 2017.

19. Dong Y, Huo X, Sun R, Liu Z, Huang M and Yang S: LncRNA Gm15290 promotes cell proliferation and invasion in non-small cell lung cancer through directly interacting with and suppressing the tumor suppressor miR-615-5p. Oncol Res, 2017 (Epub ahead of print).

20. Hua Q, Lv X, Gu X, Chen Y, Chu H, Du M, Gong W, Wang M and Zhang Z: Genetic variants in lncRNA H19 are associated with the risk of bladder cancer in a Chinese population. Mutagenesis 31: 531-538, 2016.

21. Chen P, Wan D, Zheng D, Zheng Q, Wu F and Zhi Q: Long non-coding RNA UCA1 promotes the tumorigenesis in pancreatic cancer. Biomed Pharmacother 83: 1220-1226, 2016.

22. Chen M, Li J, Zhuang C and Cai Z: Increased lncRNA ABHD11-AS1 represses the malignant phenotypes of bladder cancer. Oncotarget 8: 28176-28186, 2017.

23. Pei Z, Du X, Song Y, Fan L, Li F, Gao Y, Wu R, Chen Y, Li W, Zhou $\mathrm{H}$, et al: Down-regulation of lncRNA CASC2 promotes cell proliferation and metastasis of bladder cancer by activation of the Wnt/ $\beta$-catenin signaling pathway. Oncotarget 8: 18145-18153, 2017.

24. Tam OH, Aravin AA, Stein P, Girard A, Murchison EP, Cheloufi S, Hodges E, Anger M, Sachidanandam R, Schultz RM and Hannon GJ: Pseudogene-derived small interfering RNAs regulate gene expression in mouse oocytes. Nature 453: 534-538, 2008.

25. Watanabe T, Totoki Y, Toyoda A, Kaneda M, Kuramochi-Miyagawa S, Obata Y, Chiba H, Kohara Y, Kono T, Nakano T, et al: Endogenous siRNAs from naturally formed dsRNAs regulate transcripts in mouse oocytes. Nature 453: $539-543,2008$.

26. Haudenschild DR, Chen J, Pang N, Steklov N, Grogan SP, Lotz MK and D'Lima DD: Vimentin contributes to changes in chondrocyte stiffness in osteoarthritis. J Orthop Res 29: 20-25, 2011.

This work is licensed under a Creative Commons Attribution-NonCommercial-NoDerivatives 4.0 International (CC BY-NC-ND 4.0) License. 